Article

\title{
Toward Superhydrophobic/Superoleophilic Materials for Separation of Oil/Water Mixtures and Water-in-Oil Emulsions Using Phase Inversion Methods
}

\author{
Chih-Feng Wang ${ }^{1, *(\mathbb{D})}$, Yi-Jung Tsai ${ }^{2}$, Shiao-Wei Kuo ${ }^{3}$, Kuo-Jung Lee ${ }^{2}$, Chien-Chieh $\mathrm{Hu}^{1}$ and \\ Juin-Yih Lai ${ }^{1,4,5}$ \\ 1 Graduate Institute of Applied Science and Technology, National Taiwan University of Science and \\ Technology, Taipei 106, Taiwan; cchu@mail.ntust.edu.tw (C.-C.H.); jylai@mail.ntust.edu.tw (J.-Y.L.) \\ 2 Department of Materials Science and Engineering, I-Shou University, Kaohsiung 840, Taiwan; \\ kitttty830317@gmail.com (Y.-J.T.); krlee@isu.edu.tw (K.-J.L.) \\ 3 Department of Materials and Optoelectronic Science, National Sun Yat-Sen University, Kaohsiung 804, \\ Taiwan; kuosw@faculty.nsysu.edu.tw \\ 4 Department of Chemical Engineering, National Taiwan University of Science and Technology, \\ Taipei 106, Taiwan \\ 5 R\&D Centre for Membrane Technology, Chung Yuan University, Taoyuan 320, Taiwan \\ * Correspondence: cfwang@mail.ntust.edu.tw; Tel.: +886-2-2730-1210; Fax: +886-2-2730-3733
}

Received: 7 September 2018; Accepted: 10 November 2018; Published: 11 November 2018

\begin{abstract}
In this study, a method that can simultaneously separate oil/water mixtures and water-in-oil emulsions were developed. Various substrates (synthetic polymers and stainless steel meshes) were coated by rough hydrophobic polymer films. The prepared materials possessed superhydrophobicity and superoleophilicity. These superhydrophobic sponges can isolate extensive amounts of oil from water when connected to a related vacuum framework. Moreover, the superhydrophobic meshes (SHM) can separate both surfactant-free and -stabilized water-in-oil emulsions via gravity with high separation efficiency (oil purity: $>99.99 \%$ ) and flux (up to $4760 \mathrm{~L} \mathrm{~m}^{-2} \mathrm{~h}^{-1}$ ). The extraordinary performance of our materials and their low-energy, efficient, low-cost preparation propose that they have great potential for real-time applications.
\end{abstract}

Keywords: superhydrophobic; superoleophilic; polymer; continuous separation; emulsion separation

\section{Introduction}

Industrial development has posed tremendous risks to affect terrestrial ecosystems and human health due to oil-spill accidents and an increasing aggregate of oily wastewater [1,2]. The international tanker owners pollution federation (ITOPE) revealed that overview 1800 big oil tanker accidents from 1970 to 2017 resulted in around 5.74 million tons of spilled oil in the world. The total volume of oil lost to the environment in 2017 was approximately 7000 tons. Therefore, emulsified oil/water separation is an important and urgent task because of environmental and economic demands. Current cleanup technologies for oil spill remediation include in-situ burning, bioremediation, as well as the use of oil-absorbing materials, oil skimmers, and oil containment booms (e.g., silica, activated carbon, organophilic clays, synthetic polymers) [3-6]. However, these oil/water separation methods still suffer from slow adsorption kinetics, low selectivity, poor recyclability, tedious processing, and secondary pollution.

Recently, superwetting materials that exhibit superhydrophobicity and superoleophilicity have grown into attractive options because of their ability to efficiently separate or selectively adsorb oil (or other hydrophobic organic solvents) from the water [7-15]. Liu et al. prepared a graphene- 
melamine sponge through a microwave irradiation method [16]. The prepared sponges possessed superhydrophobicity and superoleophilicity and exhibited very high absorption capacities for oils and organic solvents, excellent selectivity, and recyclability. Xiang and coworkers detailed a one-step fabrication to prepare superhydrophobic and superoleophilic melamine sponges with outstanding absorbency and flame-retardancy [17]. The prepared sponges absorb an extensive scope of organic solvents proficiently and with high selectivity. Lu et al. employed a green freeze-drying method to prepare superhydrophobic and superoleophilic ethyl cellulose sponges [18], which were relevant to water/oil separation. All the more as of late, superhydrophobic furfuryl alcohol-modified melamine sponges were set up for the fruitful separation and adsorption of oils and organic solvents [19].

Most previous studies have focused exclusively on the oil adsorption capacity of the developed materials, with the spilled oil usually removed using mechanical squeezing procedures, distillation, or solvent washing methods. These methods are all time-consuming, tedious, and energy-demanding, thereby limiting their practical applicability. In addition, even if the vast majority of these materials can encourage immiscible oil/water separation, they are not relevant for isolating water in oil emulsions in light of the fact that the pore sizes of these materials $(>50 \mu \mathrm{m})$ were too large to hold emulsified water droplets $<20 \mu \mathrm{m}$. Accordingly, there is still a critical need to develop new strategies and materials to meet the stringent standard for the separations of oil/water blends and surfactant-balanced out emulsions.

In this studies, we present a nonsolvent-induced phase inversion method to synthesize a rough hydrophobic polymer coating and attach it onto different porous substrates, such as a polyurethane (PU) sponge, melamine sponge, and stainless-steel mesh to efficiently separate an oil/water mixture to surfactant-free and -stabilized water-in-oil emulsions (Scheme 1). The phase inversion methods could be used to prepare superhydrophobic materials efficiently [20-23]. The superhydrophobic sponges absorbed an expansive assortment of oils and organic solvents with high selectivity. Because of their superhydrophobicity and superoleophilicity, these sponges can be utilized within to a vacuum framework for the constant absorption and evacuation of oil contaminations (e.g., isooctane, n-hexadecane, and motor oil) from water surfaces. These superhydrophobic sponges also resulted in rapid oil/water separations under harsh environmental conditions (e.g., bases, acids, and salts). Moreover, we found that the superhydrophobic and superoleophilic stainless steel networks could separate both without surfactant and balanced out water-in-oil emulsions, exclusively determined by gravity, with high partition efficiencies ( $>99.99 \mathrm{wt} \%$ regarding oil immaculateness in the filtrate). The remarkable execution of our superhydrophobic composites in oil/water detachment and their straightforward readiness through a mechanically practical process makes it conceivable to apply these materials in scholarly and modern settings.

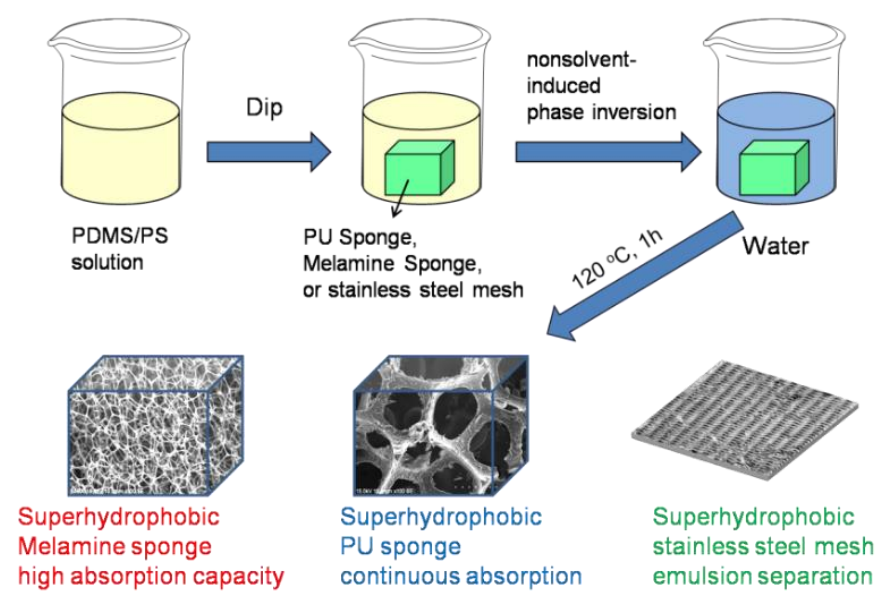

Scheme 1. Schematic of the preparation of superhydrophobic materials through a nonsolvent-induced phase inversion method. 


\section{Materials and Methods}

\subsection{Materials}

SE 1700 (polydimethylsiloxane, PDMS) was purchased from Dow Corning (Midland, MI, USA). Span 80 was supplied by Acros. Polystyrene (PS) $\left(M_{\mathrm{W}}=190,000\right)$ was purchased from Scientific Polymer Products, Inc. (Ontario, NY, USA). Melamine sponges, PU sponges, and stainless-steel meshes (1400 mesh) were directly applied using the coating procedures indicated below.

\subsection{Preparation of PDMS/PS Coated Substrates}

The superhydrophobic/superoleophilic composites were prepared using a nonsolvent-induced phase inversion method. First, a PDMS/PS solution was prepared by dissolving PDMS (0.25 g), the curing agent $(0.025 \mathrm{~g})$, and polystyrene $(0.25 \mathrm{~g})$ in tetrahydrofuran (THF) $(100 \mathrm{~mL})$. The melamine sponges, PU sponges, or stainless-steel meshes were dipped into the coating solution, followed by the removal of the residual solution with a squeezing process. Subsequently, the coated substrates were immersed in a water bath for $10 \mathrm{~min}$ to undergo phase inversion. The resulting sponges were cured in an oven $\left(120^{\circ} \mathrm{C}, 1 \mathrm{~h}\right)$.

\subsection{Water-in-Oil Emulsions}

Water-in-oil emulsions free from surfactant were set up by mixing water with an oil (n-hexane, isooctane, n-octane, or n-hexadecane; $1: 9, v: v)$, and after that, sonicating for 45 min to create a white arrangement. To prepare surfactant-balanced out water-in-oil emulsions, Span 80 (0.08 g) was broken up in oil (n-hexane, isooctane, n-octane, or n-hexadecane; $200 \mathrm{~mL})$, water $(2.0 \mathrm{~mL})$ was included, and afterward, the mixture was mixed for $3 \mathrm{~h}$.

\subsection{Water-in-Oil Emulsions Separation Experiment}

A piece of superhydrophobic stainless-steel mesh was supported by filter paper and then fixed between two glass vessels. The surfactant-free and -stabilized water-in-oil emulsions were poured into the filter, and the separation was performed, driven by gravity.

\subsection{Instruments and Characterization}

The microstructure of the superhydrophobic composite was portrayed utilizing a HITACHI S-4700 scanning electron microscope (S-4700, HITACHI, Tokyo, Japan). Static contact points and sliding edges of droplets $(5 \mu \mathrm{L})$ were estimated utilizing a FDSA MagicDroplet-100 contact angle goniometer (Sindatek Instruments Co., Ltd., Taipei, Taiwan). The water substance in the first emulsions and related gathered filtrates were resolved utilizing a MKC-500 Coulometric Karl Fischer moisture titrator (Kyoto Electronics Manufacturing Co., Ltd., Tokyo, Japan). Optical microscopy pictures were recorded utilizing an Olympus BX51M instrument (Olympus Corporation, Tokyo, Japan) in the wake of putting a drop of an emulsion arrangement onto a natural checking board.

\section{Results and Discussion}

Generally, the hydrophobicity of a surface is determined through a combination of its surface chemical composition and topographical microstructures. We anchored hydrophobic polymer coatings onto the frames of the synthetic sponges to change their wettability from hydrophobic (PU sponge, water contact angle: $130^{\circ}$, Figure 1a) or hydrophilic (melamine sponge, water contact angle: $0^{\circ}$, Figure $1 \mathrm{~b}$ ) to superhydrophobic. The superhydrophobic PU sponge and superhydrophobic melamine sponge in Figure 1c,d possessed high water contact angles $\left(162^{\circ}\right.$ and $165^{\circ}$, respectively) and superoleophilicity (contact angles of n-hexane, isooctane, n-octane, and n-hexadecane: all near $0^{\circ}$ ). Water droplets remained relatively round on the superhydrophobic surfaces and, therefore, rolled off easily. 

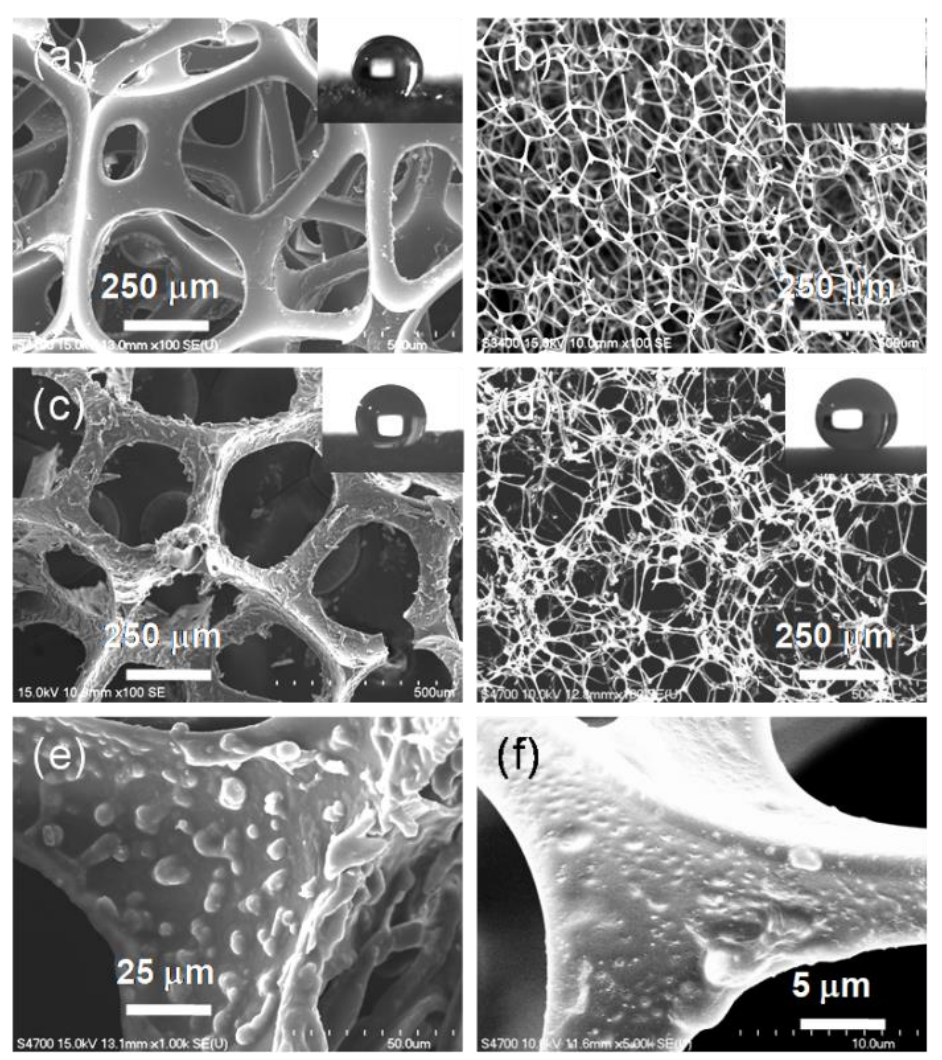

Figure 1. SEM images of the (a) polyurethane (PU) sponge; (b) melamine sponge; (c) superhydrophobic PU sponge; (d) superhydrophobic melamine sponge. Inset: photographs of water droplets on samples: (e) Enlarged view of a microstructure in (c); (f) Enlarged view of a microstructure in (d).

Scanning electron microscopy (SEM) was employed to characterize the surface morphologies of the pristine (Figure 1a,b) and hydrophobic polymer-modified (Figure 1c,d) synthetic sponges. Under higher magnification, the skeletons of superhydrophobic sponges covered by numerous nanoscale/micro protrusions consisting of hydrophobic polymers could be clearly distinguished. Compared with the smooth skeletons of the pristine sponge, the surfaces of superhydrophobic sponges (Figure 1e,f) exhibited much rougher structures. This morphology resulted in a composite interface in which air became trapped within the grooves beneath the liquid, consequently inducing superhydrophobicity. Figure S1 shows SEM images and element distribution maps of the superhydrophobic PU and melamine sponges. The Si element is well distributed on the entire sponge surface, suggesting that the skeletons of sponges were covered by hydrophobic polymer coatings. Typically, superhydrophobicity is lost that contain corrosive acids and bases. We found that our superhydrophobic sponge possessed superhydrophobic properties not only for pure water, but also for corrosive aqueous liquids, including basic $(0.1 \mathrm{M} \mathrm{NaOH})$, acidic $(0.1 \mathrm{M} \mathrm{HCl})$, and salt solutions. Droplets of these solutions remained spherical on the superhydrophobic sponge and rolled off readily.

As shown in Figure 2a, the superhydrophobic melamine sponge (SHMS) could selectively absorb oil from water once it made contact with oil/water mixtures due to its superhydrophobic/ superoleophilic properties. Therefore, the SHMS is a promising adsorbent material for selective removal of oils and organic pollutants from water. We employed the absorption capacity $(k)$ as a measure of how much oil or organic solvent the superhydrophobic melamine sponge could capture. Several organic liquids were evaluated, including n-hexane, n-octane, isooctane, and n-hexadecane. The SHMS exhibited a very high absorption capacity for these organic liquids. Figure $2 b$ shows that the SHMS could absorb concentrations of the organic liquids 60-80 times that of its own weight. The recyclability of absorbents is very important for practical applications; no obvious change in the absorption capacity was found after 50 cycles of adsorption-squeezing tests (Figure 2c), confirming the high recyclability of the SHMS. 


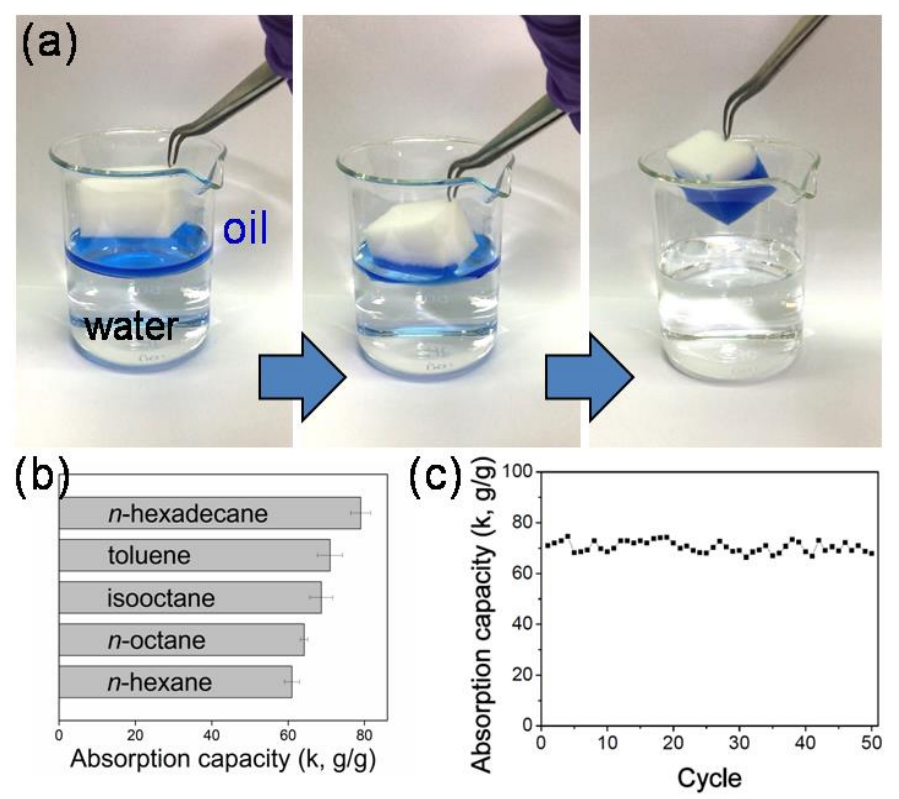

Figure 2. (a) Photographs of isooctane absorption on the water surface with the superhydrophobic melamine sponge; (b) The absorption capacity of the superhydrophobic melamine sponge for different organic solvents; (c) The absorption capacity of the sponge towards isooctane up to 50 absorption/ squeezing cycles.

In previous studies of superhydrophobic porous materials, the absorbed oil was typically removed using a squeezing operation, distillation, or a solvent washing method, all of which would have to be rehashed on incalculable occasions in a practical oil slick cleanup; the method can be to a great degree monotonous and not vitality productive. As of late, we demonstrated that pumping through superhydrophobic porous materials could be used to realize the continuous absorption and removal of organic pollutants from water surfaces, greatly decreasing the consumption of materials and simplifying the oil recovery process [24]. Because of their superhydrophobicity and superoleophilicity, our superhydrophobic PU sponges (SHPUS) could be used for the continuous removal of oil pollutants. We connected a SHPUS to a tube and placed it at the oil-water interface in a mixture of oil and water. As indicated in Figure 3a, the SHPUS quickly became saturated with the oil (isooctane) while completely repelling the water. Subsequently, we employed a vacuum system ( 0.5 bar) to remove the oil from the water surface in a continuous manner. The oil floating on the water surface was removed continuously through the sorbent until all of the oil disappeared. In addition, no water droplets were visible to the naked eye in the collected filtrate oil (Figure S2). We also performed these continuous oil/water separation experiments with viscous motor oil/water mixtures (Figure 3b) and other oil/water mixtures; all mixtures were completely separated.

Each oil/water mixture exhibited a high flux during its continuous separation test. The isooctane/ water, n-hexadecane/water, motor oil/water, and viscous motor oil/water mixtures provided comparable fluxes of 12,740,000, 3,640,000, 212,000 and 74,900 $\mathrm{L} \mathrm{m}^{-2} \mathrm{~h}^{-1} \mathrm{bar}^{-1}$, respectively (Table 1). Notably, the majority of the oil/water blends isolated utilizing the extraordinarily wettable materials created in past investigations contained unadulterated water and oil. Real industrial production and waste discharges are regularly exceptionally perplexing_as examples: strongly acidic, strongly basic, or containing salt. These intricate frameworks represent an incredible test to oil/water separation frameworks. We arranged three sorts of oil/water blends from isooctane and $0.1 \mathrm{M} \mathrm{NaOH}, 0.1 \mathrm{M} \mathrm{HCl}$, and $3.5 \mathrm{wt} \% \mathrm{NaCl}$ aqueous solutions, respectively, and then separated these oil/corrosive solution mixtures through our continuous oil/water separation system (Figures S3-S5). The flux and separation efficiency were similar to the isooctane/pure water system, suggesting good chemical stability against acids, bases, and salts. 

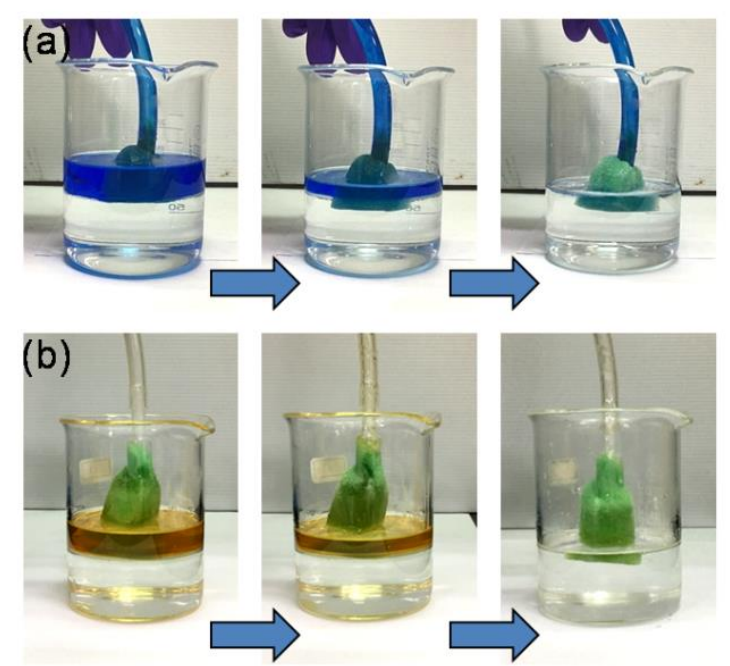

Figure 3. Photographs of the continuous absorption and removal of (a) isooctane, (b) viscous motor oil from the surfaces of water using the superhydrophobic PU sponge.

Table 1. Oil purities and fluxes of various oil/water mixtures passed through the continuous separation system.

\begin{tabular}{ccc}
\hline Oil/water Mixtures & Oil Viscosity $\left(\mathbf{m m}^{\mathbf{2}} \mathbf{s}\right)$ & Flux $\left(\mathbf{L ~ m}^{-\mathbf{2}} \mathbf{h}^{-\mathbf{1}} \mathbf{b a r} \mathbf{~}^{\mathbf{1}}\right)$ \\
\hline isooctane/water & 0.654 & $12,740,000$ \\
n-hexadecane/water & 3.526 & $3,640,000$ \\
motor oil/water & 149.3 & 212,000 \\
viscous motor oil/water & 231.7 & 74,900 \\
\hline
\end{tabular}

In most cases, wastewaters containing emulsified oil/water mixtures are much more difficult to treat than immiscible mixtures. Our superhydrophobic sponges are much less efficient and impractical when dealing with emulsified oil/water mixtures. To separate surfactant-free and -stabilized water-in-oil emulsions, a hydrophobic polymer-coated stainless-steel mesh was prepared using the aforementioned nonsolvent-induced phase inversion method. Figure $4 \mathrm{a}, \mathrm{b}$ present top-view SEM images of the stainless-steel mesh before and after modification, respectively. The mesh is wrapped in the hydrophobic polymer and compared with the original stainless-steel mesh. The higher-magnification images (Figure $4 \mathrm{c}, \mathrm{d}$ ) of the modified mesh reveals that the hydrophobic polymer exhibits a spherical shape with the diameter $<100 \mathrm{~nm}$ and "balls" stacked on top of each other, forming micro- and nanoscale binary structures. The mesh exhibits superhydrophobicity with a high water contact angle of $150^{\circ}$ and can only be selectively wetted by oil.

To test separation ability, we performed a series of water-in-oil emulsions through the superhydrophobic mesh (SHM), including surfactant-free and -stabilized emulsions. No external force was applied during this separation process, only gravity. The oil-continuous phase permeated through the SHM, causing emulsion droplets to demulsify and leave water behind, as in previous work [25]. The photographs (Figure 5a) of the emulsions and filtrates before and after separation show that the original milky feed emulsions became clear and transparent after separation. The optical microscopy images also demonstrate the effective separation, as not a single droplet is conspicuous in the entire collected filtrate, implying that the water was removed from the surfactant-free water-in-isooctane emulsion. It is noteworthy that the surfactant-free water-in-isooctane emulsion exhibited high flux across the SHM. The fluxes of the n-hexane, isooctane, n-octane, and n-hexadecane emulsions permeating though the SHM were 4760, 4072, 3920, and $3010 \mathrm{~L} \mathrm{~m}^{-2} \mathrm{~h}^{-1}$, respectively (Figure 6a). The SHM also displayed high efficiency when separating surfactant-stabilized water-in-oil emulsions. As in the separation of surfactant-free water-in-oil emulsions, we observed no water droplets in the filtrate (Figure 5b), indicating that the SHM was effective for the separation of the surfactant-stabilized 
water-in-oil emulsion. The fluxes of all surfactant-stabilized water-in-oil emulsions were 4235, 3590, 3415 , and $2140 \mathrm{~L} \mathrm{~m}^{-2} \mathrm{~h}^{-1}$ bar ${ }^{-1}$ for $\mathrm{n}$-hexane, isooctane, $\mathrm{n}$-octane, and $\mathrm{n}$-hexadecane, respectively (Figure 6a). The oil purity after a single separation was calculated by the content of water in the filtrate using a Karl Fischer Titrator and summarized in Figure 6b. The oil purities of all the separated emulsions were greater than $99.99 \mathrm{wt} \%$, demonstrating extremely high separation effectiveness. Contrasted with numerous different sorts of extraordinarily wettable materials, our SHM have high transitions and show exceptional separation efficiencies amid divisions of water-in-oil emulsions (Table 2) [26-33].
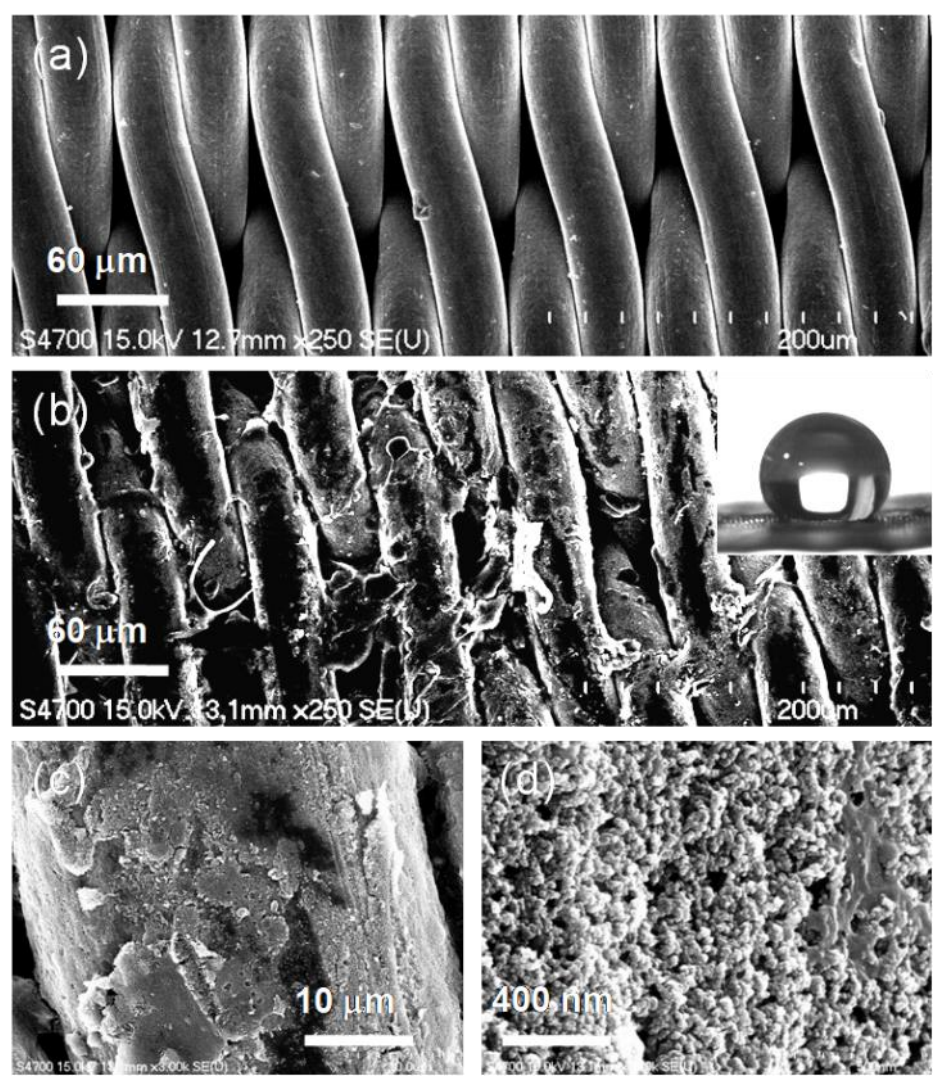

Figure 4. SEM images of (a) unmodified and (b) rough hydrophobic polymer-coated stainless-steel mesh; inset: photograph of water droplet on the mesh; (c) Enlarged view of a microstructure in (b); (d) Enlarged view of (c).

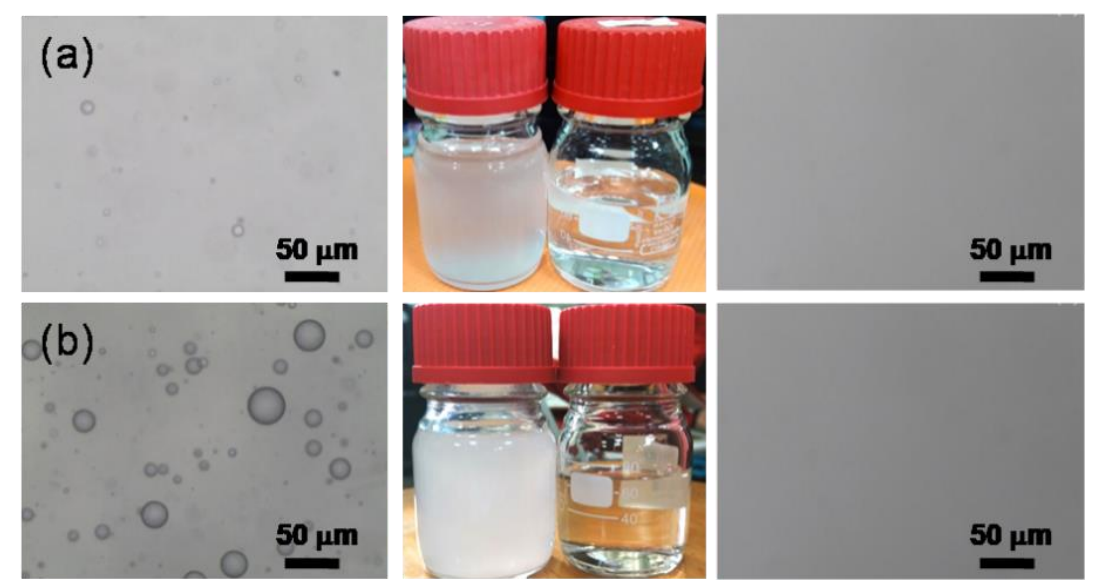

Figure 5. Photographs of (a) surfactant-free and (b) -stabilized water-in-isooctane emulsions before and after separation using a superhydrophobic mesh (SHM). 

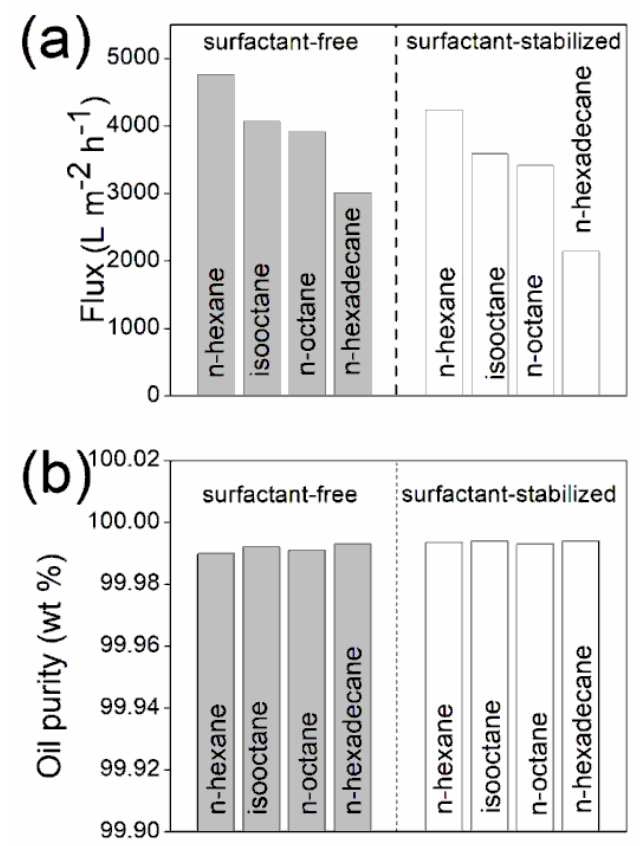

Figure 6. (a) Fluxes and (b) oil purities of filtrate after separating various surfactant-free and -stabilized water-in-oil emulsions.

Table 2. Comparison of various special wettable materials used for surfactant-stabilized water-in-oil emulsion separation.

\begin{tabular}{|c|c|c|c|}
\hline Materials & $\begin{array}{c}\text { The Flux of Surfactant } \\
\text { Stabilized Water-in-Oil } \\
\text { Emulsions }\end{array}$ & $\begin{array}{l}\text { Oil Purity } \\
\text { (wt \%) }\end{array}$ & Ref. \\
\hline $\begin{array}{l}\text { poly-(N,Ndimethylaminoethyl } \\
\text { methacrylate)/poly(divinylbenzene) modified stainless } \\
\text { steel mesh }\end{array}$ & Up to $1200 \mathrm{~L} \mathrm{~m}^{-2} \mathrm{~h}^{-1}$ & $>99.93$ & [26] \\
\hline fluorinated silica nanoparticles coated papers & $>600 \mathrm{~L} \mathrm{~m}^{-2} \mathrm{~h}^{-1}$ & $>99.9$ & [27] \\
\hline sand layer & $\mathrm{Up}$ to $2342 \mathrm{~L} \mathrm{~m}^{-2} \mathrm{~h}^{-1}$ & $>99.98$ & [28] \\
\hline $\begin{array}{l}\text { polydivinylbenzene/polydimethylsiloxane decorated } \\
\text { filter membrane }\end{array}$ & none & $>99.84$ & [29] \\
\hline superhydrophobic collagen fiber membrane & Up to $1627 \mathrm{~L} \mathrm{~m}^{-2} \mathrm{~h}^{-1}$ & $>99.99$ & [30] \\
\hline $\begin{array}{l}\text { PIM/polyhedral oligomeric silsesquioxane microfibrous } \\
\text { membranes }\end{array}$ & Up to $1097 \mathrm{~L} \mathrm{~m}^{-2} \mathrm{~h}^{-1}$ & $>99.97$ & [31] \\
\hline porous PVDF membranes & Up to $318 \mathrm{~L} \mathrm{~m}^{-2} \mathrm{~h}^{-1}$ & $>99.64$ & [32] \\
\hline porous PVDF membranes & Up to $1000 \mathrm{~L} \mathrm{~m}^{-2} \mathrm{~h}^{-1}$ & $>99.95$ & [33] \\
\hline rough hydrophobic polymer coated stainless steel mesh & $\mathrm{Up}$ to $4235 \mathrm{~L} \mathrm{~m}^{-2} \mathrm{~h}^{-1}$ & $>99.99$ & This work \\
\hline
\end{tabular}

The antifouling property is an important characteristic for materials utilized for oil/water separation. We tried the antifouling execution of our SHM by playing out a cyclic analysis for the treatment of the surfactant-settled water-in-isooctane emulsion. For each cycle, $100 \mathrm{~mL}$ of the emulsion was saturated through the SHM. As shown in Figure 7, an obvious flux decrease is observed. After washing with ethanol, the flux recovers to $85 \%$ during four cycles. The oil immaculateness in each cycle remained $>99.98 \mathrm{wt} \%$; in this way, separation proficiency was not relinquished amid these cycles. These outcomes uncover the magnificent antifouling properties of the SHM amid long-term use in the treatment of water-in-oil emulsions. 


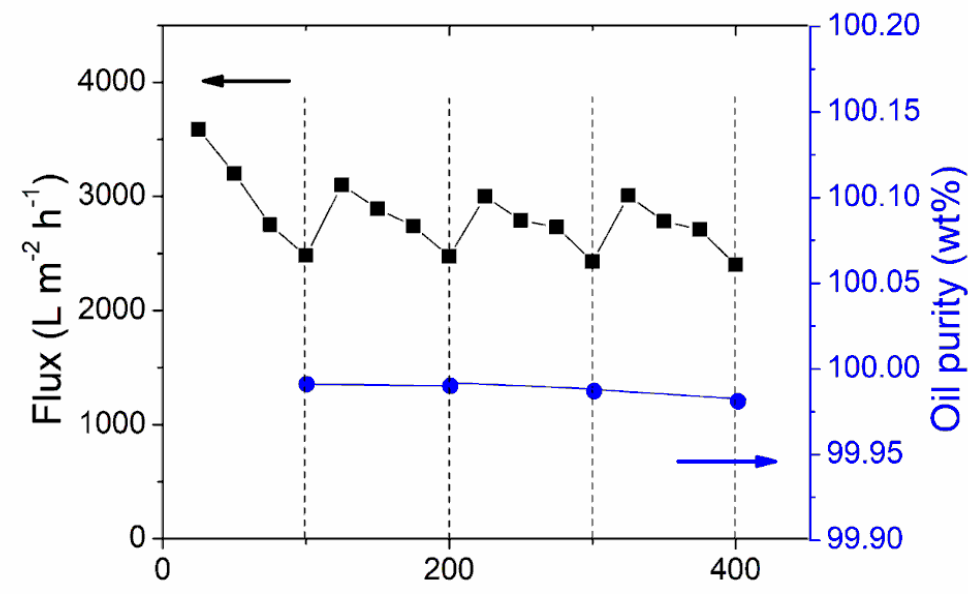

Volume of surfactant-stabilized water-in-isooctane emulsion $(\mathrm{mL})$

Figure 7. The stability monitoring in the separation flux and oil purity for the filtrate during the cycles of a surfactant-stabilized water-in-isooctane emulsion separation test using a SHM.

\section{Conclusions}

We have developed an easy, inexpensive nonsolvent-induced phase inversion method to synthesize rough hydrophobic polymer coating and apply it onto different porous substrates such as PU sponge, melamine sponge, and stainless-steel mesh to proficiently separate oil/water mixtures to surfactant-free and -stabilized water-in-oil emulsions. Superhydrophobic sponges can be used in conjunction with a vacuum system for the continuous separation of immiscible oil/water mixtures - even oil and corrosive solution mixtures—with extremely high separation efficiencies and separation capacities. Moreover, SHM allowed the effective separation of surfactant-free and -stabilized water-in-oil emulsions with high fluxes (up to $4760 \mathrm{~L} \mathrm{~m}^{-2} \mathrm{~h}^{-1}$ ) and separation efficiencies (oil purity: $>99.99 \%$ ). We believe that our special wettable materials are favorable for practical use in the treatment of industrial wastewater, providing high-quality water as a result.

Supplementary Materials: The following are available online at http:/ /www.mdpi.com/2079-6412/8/11/396/s1: Figure S1: SEM images and element distribution maps of (a) the superhydrophobic PU sponge, (b) the superhydrophobic melamine sponge; Figure S2: Photograph of the oil collected via the continuous absorption and removal of isooctane from the water surface; Figure S3: Photographs of the continuous absorption and removal of isooctane oil from the surfaces of $0.1 \mathrm{M} \mathrm{HCl}_{(\mathrm{aq})}$ using the superhydrophobic PU sponge; Figure S4: Photographs of the continuous absorption and removal of isooctane oil from the surfaces of $0.1 \mathrm{M} \mathrm{NaOH}_{(\mathrm{aq})} \mathrm{using}$ the superhydrophobic PU sponge; Figure S5: Photographs of the continuous absorption and removal of isooctane oil from the surfaces of $3.5 \mathrm{wt} \% \mathrm{NaCl}_{(\mathrm{aq})}$ using the superhydrophobic PU sponge.

Author Contributions: Conceptualization, C.-F.W. and S.-W.K.; Methodology, C.-F.W., Y.-J.T., and K.-J.L.; Formal Analysis, C.-F.W. and K.-J.L.; Investigation, C.-F.W. and Y.-J.T.; Resources, C.-F.W.; Data Curation, C.-F.W. and Y.-J.T.; Writing-Original Draft Preparation, C.-F.W.; Writing-Review \& Editing, C.-F.W., C.-C.H., and J.-Y.L.; Visualization, C.-F.W., C.-C.H., and J.-Y.L.; Supervision, C.-F.W.; Project Administration, C.-F.W.; Funding Acquisition, C.-F.W., S.-W.K., and J.-Y.L.

Funding: This study was supported financially by the Industrial Technology Research Institute, Ministry of Science and Technology, Taiwan, Republic of China (MOST 107-2221-E-011-150 and MOST 107-2218-E-011-011).

Conflicts of Interest: The authors declare no conflict of interest.

\section{References}

1. Dalton, T.; Jin, D. Extent and Frequency of Vessel Oil Spills in Us Marine Protected Areas. Mar. Pollut. Bull. 2010, 60, 1939-1945. [CrossRef] [PubMed]

2. Yip, T.L.; Talley, W.K.; Jin, D. The Effectiveness of Double Hulls in Reducing Vessel-Accident Oil Spillage. Mar. Pollut. Bull. 2011, 62, 2427-2432. [CrossRef] [PubMed] 
3. Adebajo, M.O.; Frost, R.L.; Kloprogge, J.T.; Carmody, O.; Kokot, S. Porous Materials for Oil Spill Cleanup: A Review of Synthesis and Absorbing Properties. J. Porous Mater. 2003, 10, 159-170. [CrossRef]

4. Bayat, A.; Aghamiri, S.F.; Moheb, A.; Vakili-Nezhaad, G.R. Oil Spill Cleanup from Sea Water by Sorbent Materials. Chem. Eng. Technol. 2005, 28, 1525-1528. [CrossRef]

5. Sayari, A.; Hamoudi, S.; Yang, Y. Applications of Pore-Expanded Mesoporous Silica. 1. Removal of Heavy Metal Cations and Organic Pollutants from Wastewater. Chem. Mater. 2005, 17, 212-216. [CrossRef]

6. Ono, T.; Sugimoto, T.; Shinkai, S.; Sada, K. Molecular Design of Superabsorbent Polymers for Organic Solvents by Crosslinked Lipophilic Polyelectrolytes. Adv. Funct. Mater. 2008, 18, 3936-3940. [CrossRef]

7. Li, Z.T.; Lin, B.; Jiang, L.W.; Lin, E.C.; Chen, J.; Zhang, S.J.; Tang, Y.W.; He, F.A.; Li, D.H. Effective Preparation of Magnetic Superhydrophobic Fe3o4/Pu Sponge for Oil-Water Separation. Appl. Surf. Sci. 2018, 427, 56-64. [CrossRef]

8. Zhang, X.; Zhi, D.F.; Zhu, W.Z.; Sathasivam, S.; Parkin, I.P. Facile Fabrication of Durable Superhydrophobic Sio2/Polyurethane Composite Sponge for Continuous Separation of Oil from Water. RSC Adv. 2017, 7, 11362-11366. [CrossRef]

9. Gao, J.F.; Song, X.; Huang, X.W.; Wang, L.; Li, B.; Xue, H.G. Facile Preparation of Polymer Microspheres and Fibers with a Hollow Core and Porous Shell for Oil Adsorption and Oil/Water Separation. Appl. Surf. Sci. 2018, 439, 394-404. [CrossRef]

10. Tran, V.H.T.; Lee, B.K. Novel Fabrication of a Robust Superhydrophobic Pu@Zno@Fe3o4@Sa Sponge and Its Application in Oil-Water Separations. Sci. Rep. 2017, 7, 17520. [CrossRef] [PubMed]

11. Cao, N.; Yang, B.; Barras, A.; Szunerits, S.; Boukherroub, R. Polyurethane Sponge Functionalized with Superhydrophobic Nanodiamond Particles for Efficient Oil/Water Separation. Chem. Eng. J. 2017, 307, 319-325. [CrossRef]

12. Wang, Y.K.; Wang, B.; Wang, J.H.; Ren, Y.F.; Xuan, C.Y.; Liu, C.T.; Shen, C.Y. Superhydrophobic and Superoleophilic Porous Reduced Graphene Oxide/Polycarbonate Monoliths for High-Efficiency Oil/Water Separation. J. Hazard. Mater. 2018, 344, 849-856. [CrossRef] [PubMed]

13. Liu, C.T.; Su, P.K.; Hu, C.C.; Lai, J.Y.; Liu, Y.L. Surface Modification of Porous Substrates for Oil/Water Separation Using Crosslinkable Polybenzoxazine as an Agent. J. Membr. Sci. 2018, 546, 100-109. [CrossRef]

14. Zhang, L.; Li, H.Q.; Lai, X.J.; Su, X.J.; Liang, T.; Zeng, X.R. Thiolated Graphene-Based Superhydrophobic Sponges for Oil-Water Separation. Chem. Eng. J. 2017, 316, 736-743. [CrossRef]

15. Wang, C.F.; Tzeng, F.S.; Chen, H.G.; Chang, C.J. Ultraviolet-Durable Superhydrophobic Zinc Oxide-Coated Mesh Films for Surface and Underwater-Oil Capture and Transportation. Langmuir 2012, 28, 10015-10019. [CrossRef] [PubMed]

16. Liu, W.L.; Jiang, H.B.; Ru, Y.; Zhang, X.H.; Qiao, J.L. Conductive Graphene-Melamine Sponge Prepared Via Microwave Irradiation. ACS Appl. Mater. Interfaces 2018, 10, 24776-24783. [CrossRef] [PubMed]

17. Xiang, Y.Q.; Pang, Y.Y.; Jiang, X.M.; Huang, J.; Xi, F.; Liu, J.Y. One-Step Fabrication of Novel Superhydrophobic and Superoleophilic Sponge with Outstanding Absorbency and Flame-Retardancy for the Selective Removal of Oily Organic Solvent from Water. Appl. Surf. Sci. 2018, 428, 338-347. [CrossRef]

18. Lu, Y.Q.; Yuan, W.Z. Superhydrophobic/Superoleophilic and Reinforced Ethyl Cellulose Sponges for Oil/Water Separation: Synergistic Strategies of Cross-Linking, Carbon Nanotube Composite, and Nanosilica Modification. ACS Appl. Mater. Interfaces 2017, 9, 29167-29176. [CrossRef] [PubMed]

19. Feng, Y.; Wang, Y.Y.; Wang, Y.Q.; Yao, J.F. Furfuryl Alcohol Modified Melamine Sponge for Highly Efficient Oil Spill Clean-up and Recovery. J. Mater. Chem. A 2017, 5, 21893-21897. [CrossRef]

20. Shi, J.; Alves, N.M.; Mano, J.F. Towards Bioinspired Superhydrophobic Poly(L-Lactic Acid) Surfaces Using Phase Inversion-Based Methods. Bioinspiration Biomim. 2008, 3, 034003. [CrossRef] [PubMed]

21. Bayer, I.S.; Steele, A.; Martorana, P.; Loth, E.; Robinson, S.J.; Stevenson, D. Biolubricant Induced Phase Inversion and Superhydrophobicity in Rubber-Toughened Biopolymer/Organoclay Nanocomposites. Appl. Phys. Lett. 2009, 95, 063702. [CrossRef]

22. Vogelaar, L.; Lammertink, R.G.H.; Wessling, M. Superhydrophobic Surfaces Having Two-Fold Adjustable Roughness Prepared in a Single Step. Langmuir 2006, 22, 3125-3130. [CrossRef] [PubMed]

23. Munirasu, S.; Banat, F.; Durrani, A.A.; Abu Haija, M. Intrinsically Superhydrophobic PVDF Membrane by Phase Inversion for Membrane Distillation. Desalination 2017, 417, 77-86. [CrossRef] 
24. Wang, C.F.; Lin, S.J. Robust Superhydrophobic/Superoleophilic Sponge for Effective Continuous Absorption and Expulsion of Oil Pollutants from Water. ACS Appl. Mater. Interfaces 2013, 5, 8861-8864. [CrossRef] [PubMed]

25. Shi, Z.; Zhang, W.B.; Zhang, F.; Liu, X.; Wang, D.; Jin, J.; Jiang, L. Ultrafast Separation of Emulsified Oil/Water Mixtures by Ultrathin Free-Standing Single-Walled Carbon Nanotube Network Films. Adv. Mater. 2013, 25, 2422-2427. [CrossRef] [PubMed]

26. Cai, Y.H.; Chen, D.Y.; Li, N.J.; Xu, Q.F.; Li, H.; He, J.H.; Lu, J.M. A Facile Method to Fabricate a Double-Layer Stainless Steel Mesh for Effective Separation of Water-in-Oil Emulsions with High Flux. J. Mater. Chem. A 2016, 4, 18815-18821. [CrossRef]

27. Ge, D.T.; Yang, L.L.; Wang, C.B.; Lee, E.; Zhang, Y.Q.; Yang, S. A Multi-Functional Oil-Water Separator from a Selectively Pre-Wetted Superamphiphobic Paper. Chem. Commun. 2015, 51, 6149-6152. [CrossRef] [PubMed]

28. Li, J.; Xu, C.C.; Guo, C.Q.; Tian, H.F.; Zha, F.; Guo, L. Underoil Superhydrophilic Desert Sand Layer for Efficient Gravity-Directed Water-in-Oil Emulsions Separation with High Flux. J. Mater. Chem. A 2018, 6, 223-230. [CrossRef]

29. Li, Y.; Zhang, Z.Z.; Wang, M.K.; Men, X.H.; Xue, Q.J. One-Pot Fabrication of Nanoporous Polymer Decorated Materials: From Oil-Collecting Devices to High-Efficiency Emulsion Separation. J. Mater. Chem. A 2017, 5, 5077-5087. [CrossRef]

30. Ye, X.X.; Ke, L.; Wang, Y.P.; Gao, K.Y.; Cui, Y.W.; Wang, X.L.; Huang, X.; Shi, B. Polyphenolic-ChemistryEnabled, Mechanically Robust, Flame Resistant and Superhydrophobic Membrane for Separation of Mixed Surfactant-Stabilized Emulsions. Chemistry 2018, 24, 10953-10958. [CrossRef] [PubMed]

31. Zhang, C.L.; Li, P.; Cao, B. Electrospun Microfibrous Membranes Based on Pim-1/Poss with High Oil Wettability for Separation of Oil-Water Mixtures and Cleanup of Oil Soluble Contaminants. Ind. Eng. Chem. Res. 2015, 54, 8772-8781. [CrossRef]

32. Chen, L.W.; Si, Y.F.; Zhu, H.; Jiang, T.; Guo, Z.G. A Study on the Fabrication of Porous Pvdf Membranes by in-Situ Elimination and Their Applications in Separating Oil/Water Mixtures and Nano-Emulsions. J. Membr. Sci. 2016, 520, 760-768. [CrossRef]

33. Zhang, W.B.; Shi, Z.; Zhang, F.; Liu, X.; Jin, J.; Jiang, L. Superhydrophobic and Superoleophilic Pvdf Membranes for Effective Separation of Water-in-Oil Emulsions with High Flux. Adv. Mater. 2013, 25, 2071-2076. [CrossRef] [PubMed] 